\title{
Solid Lipid Nanoparticles (SLN): Method, Characterization and Applications
}

\author{
*Akanksha Garud, Deepti Singh, Navneet Garud \\ Department of Pharmaceutics, Institute of Professional Studies, College of Pharmacy, Gwalior, Madhya Pradesh 474002, India
}

\begin{abstract}
Solid lipid nanoparticles (SLN) have emerged as a next-generation drug delivery system with potential applications in pharmaceutical field, cosmetics, research, clinical medicine and other allied sciences. Recently, increasing attention has been focused on these SLN as colloidal drug carriers for incorporating hydrophilic or lipophilic drugs. Proteins and antigens intended for therapeutic purposes may be incorporated or adsorbed onto SLN, and further administered by parenteral routes or be alternative routes such as oral, nasal and pulmonary. The obstacles associated with conventional chemotherapy may be partially overcome by encapsulating them as SLN. The present review focuses on the utility of SLN in terms of their advantages, production methodology, characterization and applications. If properly investigated, SLNs may open new vistas in therapy of complex diseases.
\end{abstract}

Key Words: Solid lipid nanoparticles, drug delivery, drug incorporation.

\section{INTRODUCTION}

Targeted delivery of a drug molecule to specific organ sites is one of the most challenging research areas in pharmaceutical sciences. By developing colloidal delivery systems such as liposomes, micelles and nanoparticles, new frontiers have opened for improving drug delivery. Nanoparticles with their special characteristics small particle size, large surface area and the capability of changing their surface properties have numerous advantages compared with other delivery systems (Kreuter, 1997). Nanoparticles are solid colloidal particles ranging from 10 to $1000 \mathrm{~nm}(1.0 \mu \mathrm{m})$, in which the active principles (drug or biologically active material) are dissolved, entrapped, and/or to which the active principle is adsorbed or attached (Chowdary et al., 1997). In recent years, significant effort has been devoted to develop nanotechnology for drug delivery, since it offers a suitable means of delivering small molecular weight drugs, as well as macromolecules such as proteins, peptides or genes

\footnotetext{
*Corresponding Author:

Akanksha Garud, Associate Professor

Department of Pharmaceutics

Institute of Professional Studies, College of Pharmacy

Gwalior, Madhya Pradesh 474002, India

E-mail: akanksha.garud@gmail.com

Contact No.: 91-9425735226
}

to cells and tissues and prevents them against enzymatic degradation (Rao et al., 2004). The advantages of nanoparticles as drug delivery systems are that they are biodegradable, non-toxic, and capable of being stored for longer periods as they are more stable (Chowdary et al., 1997).

Since a decade, trials are being made to utilize solid lipid nanoparticles (SLN) as alternative drug delivery system to colloidal drug delivery systems such as lipid emulsions, liposomes and polymeric nanoparticles. SLN combines the advantages of different colloidal carriers and also avoids some of their disadvantages. SLN can be used to improve the bioavailability of drugs, e.g. cyclosporine A (Muller et al., 2008), and to obtain sustained release of lipophilic drugs like camptothecin (Yang et al., 1999).

Solid lipid nanoparticles (SLN) are aqueous colloidal dispersions, the matrix of which comprises of solid biodegradable lipids (Swathi et al., 2010). SLNs combine the advantages and avoid the drawbacks of several colloidal carriers of its class such as physical stability, protection of incorporated labile drugs from degradation, controlled release, excellent tolerability (Sarathchandiran, 2012). SLN formulations for various application routes (parenteral, oral, 
dermal, ocular, pulmonar, rectal) have been developed and thoroughly characterized in vitro and in vivo (Mulla et al., 2010).

\section{Advantages of SLN}

- Use of biodegradable physiological lipids which decreases the danger of acute and chronic toxicity and avoidance of organic solvents in production methods (Rupenagunta et al., 2011)

- Improved bioavailability of poorly water soluble molecules (Fahr and Liu, 2007)

- $\quad$ Site specific delivery of drugs, enhanced drug penetration into the skin via dermal application

- Possibility of scaling up.

- Protection of chemically labile agents from degradation in the gut and sensitive molecules from outer environment

- SLNs have better stability compared to liposomes

- Enhance the bioavailability of entrapped bioactive and chemical production of labile incorporated compound.

- High concentration of functional compound achieved.

- Lyophilization possible

\section{Disadvantages of SLN}

- Poor drug loading capacity,

- Drug expulsion after polymeric transition during storage

- Relatively high water content of the dispersions (7099.9\%) (Schwarz et al., 1994).

\section{METHODS OF PREPARATION}

\section{High shear homogenization (HSH)}

Initially used for the production of solid lipid nanoemulsions, this method is reliable. It involves high pressure homogenization which pushes the liquid with high pressure (100-2000 bar) through a narrow gap ranging a few microns. The fluid accelerates to a very short distance at very high viscosity of over $1000 \mathrm{~km} / \mathrm{h}$. Very high shear stress and cavitation forces disrupt the particles down to submicron range. As low as 5\% to as high as of $40 \%$ lipid content has been investigated. Two general approaches to achieve $\mathrm{HSH}$ are hot homogenization and cold homogenization.
Hot homogenization is generally carried out at temperatures above the melting point of the lipid. A pre-emulsion of the drug loaded lipid melt and the aqueous emulsifier phase (same temperature) is obtained by high shear mixing device. The resultant product is hot $\mathrm{o} / \mathrm{w}$ emulsion and the cooling of this emulsion leads to crystallization of the lipid and the formation of SLNs. Smaller particle sizes are obtained at higher processing temperatures because of lowered viscosity of the lipid phase. However, high temperature leads to the degradation rate of the drug and the carrier. Increasing the homogenization temperature or the number of cycles often results in an increase of the particle size due to high kinetic energy of the particles. Generally, 3-5 homogenization cycles at a pressure of 500-1500 bar are used (Mehnert and Mader, 2001; Jenning et al., 2002).

Cold homogenization has been developed to overcome the temperature related degradation problems, loss of drug into the aqueous phase and partitioning associated with hot homogenization method. Unpredictable polymeric transitions of the lipid due to complexity of the crystallization step of the nanoemulsion resulting in several modifications and/or super cooled melts. Here, drug is incorporated into melted lipid and the lipid melt is cooled rapidly using dry ice or liquid nitrogen. The solid material is ground by a mortar mill. The prepared lipid microparticles are then dispersed in a cold emulsifier solution at or below room temperature. The temperature should be regulated effectively to ensure the solid state of the lipid during homogenization. However, compared to hot homogenization, larger particle sizes and a broader size distribution are typical of cold homogenization samples (Ekambaram et al., 2012).

\section{Ultrasonication}

Ultrasonication or high speed homogenization is another method for the production of SLNs. The advantage of this method is that the equipment used is commonly available at lab scale. However, this method suffers from problems such as broader size distribution ranging into micrometer range. Potential metal contaminations, physical instability like particle growth upon storage are other drawbacks associated with this technique (Elldem et al., 1991). 
Table 1: A list of drugs and polymers used for the preparation of SLNs using different methods.

\begin{tabular}{|c|c|c|c|}
\hline Drug & Polymer & Method of preparation & Reference \\
\hline Olanzapine & $\begin{array}{l}\text { Hydrogenated } \\
\text { soyaphosphatidylcholine }\end{array}$ & $\begin{array}{l}\text { Modified high pressure } \\
\text { homogenization }\end{array}$ & Vivek et al. (2007) \\
\hline Rizatriptan & Tristearin,Phospholipon 80 & $\begin{array}{l}\text { Modified solvent injection } \\
\text { method }\end{array}$ & Nair et al. (2011) \\
\hline Alendronate NP & PLGA,Ethyl acetate, PF68 & $\begin{array}{l}\text { Double emulsion solvent } \\
\text { diffusion }\end{array}$ & Cohen-Sela et al. (2009) \\
\hline Clozapine & Dynasan114,116, & Hot homogenization & Venkateswarlu et al. (2004) \\
\hline Tetracaine, & Tristearin,Dynasan112, & & Zur Muhlen et al.(1998) \\
\hline Etomidate, & Campritol 888ATO, & & Schwarz et al. (1994) \\
\hline Prednisolone & Lipoid S75 & & \\
\hline Vitamin A & Compritol 888ATO, Miglyol 812, & Hot homogenization & Muller et al. (1999) \\
\hline Retinol & Dynasan 116 & & Jenning et al. (2000) \\
\hline Gatifloxacin & Chitosan-Na aliginate & Modified Coacervation & Motwani et al. (2008) \\
\hline Insulin & PEG'Glycolgrafted chitosan & Ionic gelation & Zhang et al. (2008) \\
\hline Paclitaxel & Tripalmitin, phosphatidylcholine & Microemulsion & Cavalli et al. (2000) \\
\hline Insulin & $\begin{array}{l}\text { Hydrophobized cholesterol bearing } \\
\text { pullulan }\end{array}$ & Ultra sonication & Akiyoshi et al. (1998) \\
\hline Mitoxantrone & $\begin{array}{l}\text { Glyceryl behenate, Campritol } \\
\text { 888ATO, lecithin }\end{array}$ & & Lu et al. (2006) \\
\hline Vinpocetine & $\begin{array}{l}\text { Glyceryl monostearate,DCM, } \\
\text { soyalecithin }\end{array}$ & $\begin{array}{l}\text { Ultrasonic solvent } \\
\text { emulsification }\end{array}$ & Luo et al. (2006) \\
\hline Insulin & Cetyl palmitate & $\begin{array}{l}\text { Solvent emulsification } \\
\text { evaporation }\end{array}$ & Sarmento et al. (2007) \\
\hline 5-Fluorouracil & $\begin{array}{l}\text { Dynasan } 114,118, \text { triglyceride, } \\
\text { soyalecithin }\end{array}$ & $\begin{array}{l}\text { Double emulsion Solvent } \\
\text { evaporation }\end{array}$ & Yassin et al. (2010) \\
\hline Methotrexate & $\begin{array}{l}\text { Cetyl alcohol, Campritol } 888 \\
\text { ATO,Tween } 80\end{array}$ & $\begin{array}{l}\text { Microemulsion congealing } \\
\text { technique }\end{array}$ & Misra et al. (2002) \\
\hline Gatifloxacin & Sodium alginate, Chitosan & Modified coacervation & Motwani et al. (2008) \\
\hline
\end{tabular}

\section{Microemulsion based SLN preparation}

Gasco and coworkers (1997) developed SLNs based on the dilution of microemulsions. These are made stirring an optically transparent mixture at $65-70^{\circ} \mathrm{C}$ which is typically composed of a low melting fatty acid like stearic acid, an emulsifier (e.g. polysorbate 20 , polysorbate 60 , soyaphosphatydylcholine and taurodeoxycholic acid sodium salt), co-emulsifiers (e.g. butanol, sodium monooctylphosphate) and water. The hot microemulsion is dispersed in cold water $\left(2-3^{\circ} \mathrm{C}\right)$ under stirring (Waghmare et al., 2012). Typical volume ratios of the hot microemulsion to cold water are in the range of 1:25 to 1:50. The dilution process is critically determined by the composition of the microemulsion. The SLN dispersion can be used as granulation fluid for transferring in to solid product like tablets and pellets by granulation process, but in case of low particle content too much of water need to be removed. The nanoparticles were produced only with solvents which distribute very rapidly into the aqueous phase (acetone), while larger particle sizes were obtained with more lipophilic solvents (De Labouret et al., 1995).

\section{Supercritical Fluid technology}

This is a novel technique recently applied for the production of SLNs (Cavalli et al., 1996). A fluid is termed supercritical when its pressure and temperature exceed their respective critical value. The ability of the fluid to dissolve compounds increases. This technology comprises of several processes for nanoparticle production such as rapid expansion of supercritical solution (RESS), particles 
from gas saturated solution (PGSS), aerosol solvent extraction solvent (ASES), supercritical fluid extraction of emulsions (SFEE). The advantages of this technique includes avoidance of the use of solvents, particles obtained as a dry powder, instead of suspensions, requires mild pressure and temperature conditions. Carbon dioxide solution is the good choice as a solvent for this method (Chen et al., 2006).

\section{Solvent emulsification/evaporation}

For the production of nanoparticle dispersions by precipitation in $\mathrm{o} / \mathrm{w}$ emulsions, the lipophilic material is dissolved in water-immiscible organic solvent (cyclohexane) that is emulsified in an aqueous phase (Sjostrom et al., 1992). Upon evaporation of the solvent nanoparticle dispersion is formed by precipitation of the lipid in the aqueous medium. The mean diameter of the obtained particles was $25 \mathrm{~nm}$ with cholesterol acetate as model drug and lecithin/sodium glycocholate blend as emulsifier. The reproducibility of the result was confirmed by Siekmann and Westesen (1996), who produced the cholesterol acetate nanoparticles of mean size $29 \mathrm{~nm}$.

\section{Solvent emulsification-diffusion}

SLNs can also be produced by solvent emulsification-diffusion technique. The mean particle size depends upon lipid concentration in the organic phase and the emulsifier used. Particles with average diameters of $30-100 \mathrm{~nm}$ can be obtained by this technique. Avoidance of heat during the preparation is the most important advantage of this technique. Here, the lipid matrix is dissolved in water-immiscible organic solvent followed by emulsification in an aqueous phase. The solvent is evaporated under reduced pressure resulting in nanoparticles dispersion formed by precipitation of the lipid in aqueous medium (Muller et al., 2000 and Trotta et al, 2003).

\section{Double Emulsion}

In this method, the drug is encapsulated with a stabilizer to prevent drug partitioning to external water phase during solvent evaporation in the external water phase of $\mathrm{w} / \mathrm{o} / \mathrm{w}$ double emulsion. $\mathrm{Li}$ et al. (2010) prepared solid lipid nanoparticles loaded with bovine serum albumin (BSA) using double emulsion method.

\section{Spray Drying}

It is an alternative technique to lyophilization in order to transform an aqueous SLN dispersion into a drug product. This is a cost-effective method than lyophilization and recommends the use of lipid with melting point $>70^{\circ} \mathrm{C}$. This method causes particle aggregation due to high temperature shear forces and partial melting of the particle. According to Freitas and Mullera (1998) best results were obtained with SLN concentration of $1 \%$ in a solution of trehalose in water or $20 \%$ trehalose in ethanolwater mixtures $(10 / 90 \mathrm{v} / \mathrm{v})$.

\section{Solvent injection technique}

Here, the solid lipid is dissolved in water miscible solvent. The lipid solvent mixture is injected into stirred aqueous phase with or without surfactant. Finally, the dispersion filtered to remove excess lipid. Emulsion within the aqueous phase helps to produce lipid droplets at the site of injection and stabilize SLNs until solvent diffusion gets completed (Schubert et al., 2003). Mishra et al. (2010) prepared and evaluated SLNs using Solvent injection method for delivery of Hepatitis B surface antigen for vaccination using subcutaneous route.

\section{CHARACTERIZATION OF SLNs}

Adequate and proper characterization of the SLNs is necessary for its quality control. However, characterization of SLN is a serious challenge due to the colloidal size of the particles and the complexity and dynamic nature of the delivery system. The important parameters evaluated for the SLNs include particle size, size distribution kinetics (zeta potential), degree of crystallintity and lipid modification (polymorphism), coexistence of additional colloidal structures (miscelles, liposome, super cooled melts, drug nanoparticles), time scale of distribution processes, drug content, in-vitro drug release and surface morphology.

\section{Particle size and Zeta potential}

The physical stability of SLNs depends on their particle size. Photon correlation spectroscopy (PCS) and laser diffraction (LD) are the most powerful techniques for determination of particle size. PCS (also known as dynamic light scattering) measures the fluctuation of the intensity of the scattered light, which is caused by particle movement. The particle 
size determination by photon correlation spectroscopy (PCS) detects size range of $3 \mathrm{~nm}$ to $3 \mu \mathrm{m}$ and by laser diffraction in size range of $100 \mathrm{~nm}$ to $180 \mu \mathrm{m}$. Although PCS is a good tool to characterize nanoparticles, but is capable for the detection of larger microparticles (Pandey et al., 2005). The LD method is based on the dependence of the diffraction angle on the particle size (Fraunhofer spectra). Smaller particles cause more intense scattering at high angles compared to the larger ones.

Zeta potential measurement can be carried out using zeta potential analyzer or zetameter. Before measurement, SLN dispersions are diluted 50-fold with the original dispersion preparation medium for size determination and zeta potential measurement (Luo et al., 2006). Higher value of zeta potential may lead to deaggregation of particles in the absence of other complicating factors such as steric stabilizers or hydrophilic surface appendages. Zeta potential measurements allow predictions about the storage stability of colloidal dispersions.

\section{Electron microscopy}

Scanning electron microscopy (SEM) and transmission electron microscopy (TEM) provide way to directly observe nanoparticles. SEM is however better for morphological examination. TEM has a small size limit of detection (Meyer and Heinzelmann, 1992).

\section{Atomic force microscopy (AFM)}

In this technique, a probe tip with atomic scale sharpness is rastered across a sample to produce a topological map based on the forces at play between the tip and the surface. The probe can be dragged across the sample (contact mode), or allowed to hover just above (non contact mode), with the exact nature of the particular force employed serving to distinguish among the sub techniques. That ultrahigh resolution is obtainable with this approach, which along with the ability to map a sample according to properties in addition to size, e.g., colloidal attraction or resistance to deformation, makes AFM a valuable tool (Mukherjee et al., 2009).

\section{Dynamic light scattering (DLS)}

DLS, also known as PCS or quasi-elastic light scattering (QELS) records the variation in the intensity of scattered light on the microsecond time scale. This variation results from interference of light scattered by individual particles under the influence of Brownian motion, and is quantified by compilation of an autocorrelation function. The advantages of the method are the speed of analysis, lack of required calibration and sensitivity to submicrometer particles.

\section{Static light scattering (SLS)/Fraunhofer diffraction}

This method studies the pattern of light scattered from a solution of particles is collected and fit to fundamental electromagnetic equations in which size is the primary variable. It is fast and rugged method, but requires more cleanliness than DLS, and advance knowledge of the particles' optical qualities.

\section{Differential scanning calorimetry (DSC)}

DSC and powder X-ray diffractometry (PXRD) is performed for the determination of the degree of crystallinity of the particle dispersion. The rate of crystallinity using DSC is estimated by comparison of the melting enthalpy/g of the bulk material with the melting enthalpy/g of the dispersion (Siekmann and Westesen, 1994).

\section{Acoustic methods}

Another ensemble approach, acoustic spectroscopy, measures the attenuation of sound waves as a means of determining size through the fitting of physically relevant equations. In addition, the oscillating electric field generated by the movement of charged particles under the influence of acoustic energy can be detected to provide information on surface charge.

\section{Nuclear magnetic resonance (NMR)}

NMR can be used to determine both the size and the qualitative nature of nanoparticles. The selectivity afforded by chemical shift complements the sensitivity to molecular mobility to provide information on the physicochemical status of components within the nanoparticle.

\section{APPLICATIONS OF SLN}

SLN for Parenteral Application

Wissing et al. (2004) intensively reviewed parenteral use of SLN. SLN are very suitable for systemic delivery because they consist of physiologically well-tolerated ingredients and they have good 
storage capabilities after lyophilization and/or sterilization. When injected intravenously, SLN are sufficiently small to circulate in the microvascular system and prevent macrophage uptake in case of hydrophilic coating. Therefore, SLN have been suggested for viral and non-viral gene delivery. Cationic SLN has been demonstrated to bind genes directly via electrostatic interactions, and have potential benefits in targeted gene therapy in treatment of cancer. The charge of particles can also be modulated via the composition, thus allowing binding of oppositely charged molecules (Olbrich et al 2001; Tabatt et al., 2004; Pedersen et al 2006).

Treatment of central nervous system diseases such as brain tumors, AIDS, neurological and psychiatric disorders is often constrained by the inability of potent drugs to pass blood brain barrier (BBB). Hydrophilic coating of colloids improves the transport of these through BBB and tissue distribution (Kreuter 2001; Wang et al., 2002). Fundaro et al, 2000, prepared doxorubicin loaded stealth and nonstealth SLN and observed that the stealth nanoparticles were present in blood at higher concentrations than non-stealth SLN after $24 \mathrm{~h}$ following intravenous administration.

\section{SLN for Nasal Application}

Nasal administration was a promising alternative noninvasive route of drug administration due to fast absorption and rapid onset of drug action, avoiding degradation of labile drugs (such as peptides and proteins) in the GI tract and insufficient transport across epithelial cell layers (Lee et al., 1994). In order to improve drug absorption through the nasal mucosa, approaches such as formulation development and prodrug derivatization have been employed. SLN has been proposed as alternative transmucosal delivery systems of macromolecular therapeutic agents and diagnostics by various research groups (Muller and Keck 2004; Prego et al., 2005). In a recent report, coating polymeric nanoparticles with PEG gave promising results as vaccine carriers (Vila et al., 2004). The role of PEG coating of polylactic acid nanoparticles in improving the trans mucosal transport of the encapsulated bioactive molecule reported to be successful by Tobio et al, 1998. This concept can be useful for solid lipid nanoparticles.

\section{SLN for Respiratory Application}

The lungs offer a high surface area for drug absorption by avoiding first-pass effects. Rapid drug absorption by aerosolization of drugs (in the 1-3 $\mu \mathrm{m}$ size range) occurs since the walls of alveoli in the deep lung are extremely thin (Agu et al., 2001; Banga 2003). Lymphatic drainage plays an important role in the uptake of particulates in the respiratory system. SLN can be proposed as carriers of anticancer drugs in lung cancer treatment or peptide drugs to improve their bioavailability. Assessment of inhaled radio-labeled SLN bio distribution has been described and the data showed an important and significant uptake of the radio-labeled SLN into the lymphatic after inhalation (Videira et al., 2002). In a recent study, antitubercular drugs (rifampicin, isoniazid and pyrazinamide) were incorporated into various formulations of solid lipid particles ranged from 1.1-2.1 $\mu \mathrm{m}$ and formulations were nebulized to guinea pigs by mouth for direct pulmonary delivery (Pandey et al., 2005a and 2005b). Nebulization of solid lipid particles carrying antitubercular drugs was observed to be successful in improving drug bioavailability and reducing the dosing frequency for better management of pulmonary tuberculosis.

\section{SLN for Ocular Application}

Ocular drug administration via SLN has been reported several times (Friedrich et al 2005). Biocompatibility and mucoadhesive properties of SLN improve their interaction with ocular mucosa and prolong corneal residence time of the drug, with the aim of ocular drug targeting. Cavalli et al., (2002) evaluated SLN as carriers for ocular delivery of tobramycin in rabbit eyes. As a result SLN significantly enhanced the drug bioavailability in the aqueous humor. Cavalli et al., (1995) also studied pilocarpine delivery via SLN, which is commonly used in glaucoma treatment, earlier. They reported very similar results in order to enhance the ocular bioavailability of drug.

\section{SLN for Rectal Application}

A few reports are available on the rectal drug administration via SLN in the literature (Sznitowska et al., 2000). Sznitowska et al., 2001 incorporated diazepam into SLN for rectal administration in order to provide a rapid action. They applied SLN dispersions on rabbits and performed bioavailability 
studies. They found that lipid matrix which is solid at body temperature is not an advantageous system for diazepam rectal delivery. They decided to employ lipids which melt around body temperature in their next experiments. This area seems very open to investigation, especially when the benefits of rectal route are taken into consideration. PEG coating seems to be a promising approach on rectal delivery and consequently, enhancement of bioavailability.

\section{SLN for Topical application}

SLN and NLC are very attractive colloidal carrier systems for skin applications due to their various desirable effects on skin besides the characteristics of a colloidal carrier system. They are well suited for use on damaged or inflamed skin because they are based on non-irritant and non-toxic lipids (Wissing and Muller 2003). Researchers have reported intensively on the topical application of SLN. During the last few years, SLN and NLC have been studied with active compounds such as Vitamin E (Dingler et al., 1999), tocopherol acetate (Wissing and Muller 2001), retinol (Jenning et al., 2000), ascorbyl palmitate (Uner et al., 2005a and 2005b), clotrimazole (Souto et al., 2004), triptolide (Mei et al., 2003), phodphyllotoxin (Chen et al., 2006) and a nonsteroidal antiandrogen RU 58841 (Munster et al., 2005) for topical application. A completely new, recently discovered area of application is the use of SLN in sun-protective creams (Waghmare et al., 2012).

\section{SLN in Cancer chemotherapy}

From the last two decades several chemotherapeutic agents have been encapsulated in SLN and their invitro and in-vivo efficacy have been evaluated. Tamoxifen, an anticancer drug have been incorporated in SLN to prolong the release of drug following i.v. administration in breast cancer (Murthy, 2005). Tumor targeting has been achieved with SLN loaded with drugs like methotrexate and camptothecin. Metoxantrone SLN local injections were formulated to reduce the toxicity and improve the safety and bioefficacy of the drug in treating breast cancer and lymph node metastases (Wong et al., 2006).

\section{Oral SLN in antitubercular chemotherapy}

Antitubercular drugs such as rifampsin, isoniazide, pyrazinamide-loaded SLN systems were able to reduce the dosing frequency and improve patient compliance. Antitubercular drugs loaded SLNs were prepared using solvent diffusion technique (Pandey et al., 2005).

\section{SLN for potential agriculture application}

Essential oil extracted from Artemisia arborescens L. when incorporated in SLN, were able to reduce the rapid evaporation compared with emulsions and the systems have been used in agriculture as a suitable carrier of ecologically safe pesticide (Lai et al., 2006).

\section{REFERENCES}

Agu, R.U., Ugwoke, M.I., Armand, M., Kinget, R., Verbeke, N. (2001). The lung as a route for systemic delivery of therapeutic proteins and peptides. Respir Res 2(4): 198-209. [DOI]

Akiyoshi, K., Kobayashi, S., Shichibe, S., Mix, D., Baudys, M., Kim, S.W., Sunamoto, J. (1998). Self-assembled hydrogel nanoparticle of cholesterol-bearing pullulan as a carrier of protein drugs: Complexation and stabilization of insulin. J Control Release 54(3): 313-320. [DOI]

Banga, A.K. (2003). Delivery of protein therapeutics. Business Briefing: Pharmatech. 198-201. [DOI]

Cavalli, R., Caputo, O., Gasco, M.R. (2000). Preparation and characterization of solid lipid nanospheres containing paclitaxel. Eur J Pharm Sci 10(4): 305-309. [DOI]

Cavalli, R., Gasco, M.R., Chetoni, P., Burqalassi, S., Saettone, M.F. (2002). Solid lipid nanoparticles (SLN) as ocular delivery system for tobramycin. Int J Pharm 238(1-2): 241245. [DOI]

Cavalli, R., Marengo, E., Rodriguez, L., Gasco, M.R. (1996). Effects of some experimental factors on the production process of solid lipid nanoparticles. Eur J Pharm Biopharm 42(2): 110-115

Chowdary, K.P.R., Rao, AS. (1997). Nanoparticles as drug carriers. Indian Drugs 34(10): 549-56.

Chen, H., Chang, X., Du, D., Liu, W., Liu, J., Weng, T., Yang, Y., Xu, H., Yang, X. (2006). Podophyllotoxin-loaded solid lipid nanoparticles for epidermal targeting. J Control Release 110(2): 296-306. [DOI]

Chen, Y.J., Jin, R.X., Zhoum Y.Q., Zeng, J., Zhang, H., Feng, Q.R. (2006). Preparation of solid lipid nanoparticles loaded with Xionggui powder- supercritical carbon dioxide fluid extraction and their evaluation in vitro release. Zhongguo Zhong Yao Za Zhi 31: 376-379

Cohen-Sela, E., Chorny, M., Koroukhov, N., Danenberg, H.D. Golomb, G. (2009). A new double emulsion solvent diffusion technique for encapsulating hydrophilic molecules in PLGA nanoparticles. J Control Release 133(2): 90-95 [DOI] 
De Labouret, A., Thioune, O., Fesii, H., Devissaguet, J.P., Puiseieux, F. (1995). Application of an original process for obtaining colloidal dispersion of some coating polymers. Preparation, Characterization, industrial scaling up. Drug Develop Ind Pharm 21: 229-41 [DOI]

Dingler, A., Blum, R.P., Niehus, H., Müller, R.H., Gohla, S. (1999). Solid lipid nanoparticles (SLN ${ }^{\mathrm{TM}} /$ Lipopearls $^{\mathrm{TM}}$ ) - a pharmaceutical and cosmetic carrier for the application of vitamin E in dermal products. J Microencapsul. 16(6): 751767. [DOI]

Ekambaram, P., Abdul Hassan Sathali, A., Priyanka, K. (2012). Solid Lipid Nanoparticles: A Review. Sci Revs Chem Commun 2(1): 80-102

Elldem, T., Speiser, P., Hineal, A. (1991). Optimization of spray-dried and congealed lipid microparticles and characterization of their surface morphology by scanning electron microscopy. Pharm Res 8: 47-54 [DOI]

Fahr, A. and Liu, X. (2007). Drug delivery strategies for poorly water soluble drugs, Expert Opinion on Drug Delivery. 4(4): 403-416. [DOI]

Freitas, C., Mullera, R.H. (1998). Spray drying of solid lipid nanoparticles (SLN TM). Eur J Pharm Biopharm 46(2): 145151 [DOI]

Friedrich, I., Reichl, S., Müller-Goymann, C.C. (2005). Drug release and permeation studies of nanosuspensions based on solidified reverse micellar solutions (SRMS) Int J Pharm 305(1-2): 167-75. [DOI]

Fundaro, A., Cavalli, R., Bargoni, A., Vighetto, D., Zara, G.P., Gasco, M.R. (2000). Non-stealth and stealth solid lipid nanoparticles (SLN) carrying doxorubicin: pharmacokinetics and tissue distribution after i.v. administration to rats. Pharm Res. 42(4): 337-343. [DOI]

Gasco, M.R. (1997) Method for producing solid lipid nanospheres with warm microemulsions. Pharm Tech Eur 9: $52-58$

Jenning, V., Gysler, A., Schafer-Korting, M., Gohla, S.H. (2000). Vitamin A loaded solid lipid nanoparticles for topical use: occlusive properties and drug targeting to the upper skin. Eur J Pharm and Biopharm 49(3): 211-218 [DOI]

Jenning, V., Lippacher, A., Gohla, S.H. (2002) Medium scale production of solid lipid nanoparticles (SLN) by high pressure homogenization J Microencapsul 19: 1-10 [DOI]

Kreuter, J. (1991). Peroral administration of nanoparticles. Adv Drug Del Rev 7: 71-86. [DOI]

Kreuter, J. (2001). Nanoparticulate systems for brain delivery of drugs. Adv Drug Deliv Rev. 47(1): 65-81. [DOI]

Lai, F., Wissing, S.A., Muller, R.H., Fadda, A.M. (2006) Artemisia arborescens L. essential oil-loaded solid lipid nanoparticles for potential agriculture application: preparation and characterization. AAPS Pharm Sci Tech 7(1): E2 [DOI]
Lee, W.A., Ennis, R.D., Longenecker, J.P., Bengtsson, P. (1994). The bioavailability of intranasal salmon calcitonin in healthy volunteers with and without permeation enhancer. Pharm Res 11(5): 747-750. [DOI]

Li, Z., Li, X., Zheng, L., Lin, X., Geng, F., Yu, L. (2010) Bovine serum albumin loaded solid lipid nanoparticles prepared by double emulsion method. Chem Res Chinese Universities 26(1): 136-141

Lu, B., Xiong, S.B., Yang, H., Yin, X.D., Chao, R.B. (2006). Solid lipid nanoparticles of mitoxantrone for local injection against breast cancer and its lymphnode metastases. Eur J Pharm Sci 28(1-2): 86-95. [DOI]

Luo, Y., Chen, D., Ren, L., Zhao, X., Qin, J. (2006). Solid lipid nanoparticles for enhancing vinpocetine's oral bioavailability. J Control Release 114(1): 53-59. [DOI]

Mehnert, W., Mader, K. (2001) Solid lipid nanoparticles: Production, characterization, applications. Advanced Drug Delivery Review. 47: 165-196 [DOI]

Mei, Z., Chen, H, Weng, T., Yang, Y., Yang, X. (2003). Solid lipid nanoparticle and microemulsion for topical delivery of triptolide. Eur J Pharm Biopharm. 56(2): 189-196. [DOI]

Meyer, E., Heinzelmann, H. (1992). Scanning force microscopy. In: Wiesendanger R, Guntherodt HJ, editors. Scanning tunneling microscopy II, Surface science. New York: Springer Verlag; pp. 99-149 [DOI]

Mishra, H., Mishra, D., Mishra, P.K., Nahar, M., Dubey, V., Jain, D.K. (2010). Evaluation of solid lipid nanoparticles as carriers for delivery of Hepatitis B surface antigen for vaccination using subcutaneous route. J Pharm Pharmaceut Sci 13(4): 495-509.

Misra, A., Kalariya, M., Padhi, B.K., Chougule, M. (2002). Methotrexate-Loaded Solid Lipid Nanoparticles for Topical Treatment of Psoriasis: Formulation and Clinical Implications. Drug Deliv Technol 5: 1-13

Motwani, S.K., Chopra, S., Talegaonkar, S., Kohli, K., Ahmad, F.J., Khar, R.K. (2008). Chitosan-sodium alginate nanoparticles as submicroscopic reservoirs for ocular delivery: Formulation, optimization and in vitro characterization. Eur J Pharm Biopharm 68(3): 513-525.

Mukherjee, S., Ray, S., Thakur, R.S. (2009) Solid lipid nanoparticles (SLN): A Modern Formulation Approach in Drug Delivery System. Indian Journal of Pharmaceutical Sciences 71(4): 349-358. [DOI]

Mulla, J.S., Khazi, I.M., Jamakandi, V.G. (2010). Solid lipid nanoparticles: Potential applications IJNDD 2(3): 82-87.

Muller, R.H., Mäder, K., Gohla, S.H. (2000) Solid Lipid Nanoparticles For Controlled Drug Delivery- A Review of the State of the art. Eur J Pharm Bio Pharm 50(1): 161-177. [DOI]

Muller, R.H., Runge, S.A., Ravelli, V., Thünemann, A.F., Mehnert, W., Souto, E.B. (2008) Cyclosporine-loaded solid lipid nanoparticles (SLN): drug-lipid physicochemical 
interactions and characterization of drug incorporation. Eur J Pharm Biopharm. 68(3): 535-544 [DOI]

Muller, R.H., Dobrucki, R., Radomska, A. (1999). Solid lipid nanoparticles as a new formulation with Retinol. Acta Poloniae Pharmaceutica-Drug Research 56(2): 117-120

Muller, R.H., Keck, C.M. (2004). Challenges and solutions for the delivery of biotech drugs- a review of drug nanocrystal technology and lipid nanoparticles. J Biotechnol 113(1-3): 151-170. [DOI]

Munster, U., Nakamura, C., Haberland, A., Jores, K., Mehnert W., Rummel, S., Schaller, M., Korting, H.C., Zouboulis, ChC., Blume-Peytavi, U., Schäfer-Korting, M. (2005) RU 58841-myristate - prodrug development for topical treatment of acne and androgenic alopecia. Pharmazie. 60(1): 812.

Murthy, R.S.R. (2005) Solid lipid nanoparticles as carriers for anti-cancer drugs to solid tumours. Drug Deliv 12: 385-392

Nair, R., Kumar, K.S.A., Vishnupriya, K., Badivaddin, T. Md. Sevukarajan, M. (2011). Preparation And Characterization Of Rizatriptan Loaded Solid Lipid Nanoparticles (SLNs). J Biomed Sci and Res 3(2): 392-396.

Olbrich, C., Bakowski, U., Lehr, C.M., Müller, R.H., Kneuer, C. (2001). Cationic solid-lipid nanoparticles can efficiently bind and transfect plasmid DNA. J Control Release 77(3): 345-55. [DOI]

Pandey, R., Sharma, S., Khuller, G.K. (2005a) Oral solid lipid nanoparticle-based antitubercular chemotherapy. Tuberculosis, 85(5-6): 415-420. [DOI]

Pandey, R., Khuller, G.K. (2005b). Solid lipid particle-based inhalable sustained drug delivery system against experimental tuberculosis. Tuberculosis. 85(4): 227-234. [DOI]

Pedersen, N., Hansen, S., Heydenreich, A.V., Kristensen, H.G., Poulsen, H.S. (2006). Solid lipid nanoparticles can effectively bind DNA, streptavidin and biotinylated ligands. Eur J Pharm Biopharm 62(2): 155-62. [DOI]

Prego, C., Garcia, M., Torres, D., Alonso, M.J. (2005). Transmucosal macromolecular drug delivery. J Control Release 101(1-3): 151-162. [DOI]

Rao, G.C.S., Kumar, S.M., Mathivanan, N., Rao, M.E.B. (2004) Advances in nanoparticulate drug delivery systems. Indian Drugs 41(7): 389-95.

Rupenagunta, A., Somasundaram, I., Ravichandiram, V., Kausalya, J., Senthilnathan, B. (2011). Solid lipid nanoparticles- A versatile carrier system. J Pharm Res. 4(7): 20692075.

Sarathchandiran, I. (2012). A Review on Nanotechnology in Solid Lipid Nanoparticles IJPDT 2(1): 45-61

Sarmento B., Martins S., Ferreira D., Souto E.B. (2007). Oral insulin delivery by means of solid lipid nanoparticles. Int J Nanomedicine 2(4): 743-749.
Schubert, M.A., Muller-Goymann, C.C. (2003). Solvent injection as a new approach for manufacturing lipid nanoparticles- evaluation of the method and process parameters. Eur J Pharm Biopharm 55(1): 125-131 [DOI]

Schwarz, C., Mehnert, W., Lucks, J.S., Muller, R.H. (1994). Solid lipid nanoparticles (SLN) for controlled drug delivery I. Production, characterization and sterilization. J Control Release 30(1): 83-96. [DOI]

Siekmann, B., Westesen, K. (1994). Thermoanalysis of the recrystallization process of melt-homogenized glyceride nanoparticles. Colloids and Surf B Biointerfaces 3: 159-175 [DOI]

Siekmann, B., Westesen, K. (1996) Investigations on solid lipid nanoparticles prepared by precipitation in $\mathrm{o} / \mathrm{w}$ emulsions. Eur J Pharm Biopharm 43: 104-109

Sjostrom, B., Bergenstahl, B. (1992). Preparation of submicron drug particles in lecithin-stabilized o/w emulsions I. Model studies of the precipitation of cholesteryl acetate. Int J Pharm. 88: 53-62 [DOI]

Souto, E.B., Wissing, S.A., Barbosa, C.M., Muller, R.H. (2004) Development of a controlled release formulation based on SLN and NLC for topical clotrimazole delivery. Int J Pharm. 278(1): 71-77. [DOI]

Swathi, G., Prasanthi, N.L., Manikiran, S.S., Ramarao, N. (2010). Solid lipid nanoparticles: colloidal carrier systems for drug delivery. IJPSR 1(12): 01-16.

Sznitowska, M., Gajewska, M., Janicki, S., Radwanska, A., Lukowski, G. (2001). Bioavailability of diazepam from aqueous-organic solution, submicron emulsion and solid lipid nanoparticles after rectal administration in rabbits. Eur J Pharm Biopharm, 52(2): 159-163. [DOI]

Sznitowska, M., Janicki, S., Gajewska, M., Kulik, M. (2000). Investigation of diazepam lipospheres based on Witepsol and lecithin for oral or rectal delivery. Acta Pol Pharm, 57(1): 61-64.

Tabatt, K., Sameti, M., Olbrich, C., Müller, R.H., Lehr, C.M. (2004). Effect of cationic lipid and matrix lipid composition on solid lipid nanoparticle-mediated gene transfer. Eur J Pharm Biopharm 57(2): 155-162. [DOI]

Tobio, M., Gref, R., Sanchez, A., Langer, R., Alonso, M.J. (1998). Stealth PLA-PEG nanoparticles as protein carriers for nasal administration. Pharm Res 15(2):270-275 [DOI]

Trotta, M., Debernardi, F., Caputo, O. (2003) Preparation of Solid Lipid Nanoparticles by a solvent emulsificationdiffusion technique. Int J Pharm. 257: 153-160 [DOI]

Uner, M., Wissing, S.A., Yener, G., Muller, R.H. (2005a) Solid lipid nanoparticles (SLN) and nanostructured lipid carriers (NLC) for application of ascorbyl palmitate. Pharmazie. 60(8): 577-582.

Uner, M., Wissing, S.A., Yener, G, Muller, R.H. (2005b). Skin moisturizing effect and skin penetration of ascorbyl palmitate entrapped in solid lipid nanoparticles (SLN) and 
nanostructured lipid carriers (NLC) incorporated into hydrogel. Pharmazie. 60(10): 751-755.

Venkateswarlu, V., Manjunath, K. (2004). Preparation, characterization and in vitro release kinetics of clozapine solid lipid nanoparticles. J Control Release 95(3): 627-638 [DOI]

Videira, M.A., Botelho, M.F., Santos, A.C., Gouveia, L.F., de Lima, J.J., Almeida, A.J. (2002). Lymphatic uptake of pulmonary delivered solid lipid nanoparticles. J Drug Target 10(8): 607-613 [DOI]

Vila, A., Gill, H., McCallion, O., Alonso, M.J. (2004). Transport of PLA-PEG particles across the nasal mucosa: effect of particle size and PEG coating density. J Control Release 98(2): 231-244. [DOI]

Vivek, K., Reddy, H., Murthy, R.S.R. (2007). Investigations of the Effect of the Lipid Matrix on Drug Entrapment, In Vitro Release, and Physical Stability of Olanzapine-Loaded Solid Lipid Nanoparticles. AAPS Pharm Sci Tech 8(4): 1624 [DOI]

Waghmare, A.S., Grampurohit, N.D., Gadhave, M.V., Gaikwad, D.D., Jadhav, S.l. (2012). Solid lipid nanoparticles: A promising drug delivery System IRJP 3(4): 100107.

Wang, J.X., Sun, X., Zhang, Z.R. (2002). Enhanced brain targeting by synthesis of 3',5'-dioctanoyl-5-fl uoro-2'deoxyuridine and incorporation into solid lipid nanoparticles. Eur J Pharm Biopharm, 54(3): 285-290. [DOI]

Wissing, S.A., Müller, R.H. (2001). A novel sunscreen system based on tocopherol acetate incorporated into solid lipid nanoparticles. Int J Cosmet Sci 23(4): 233-243. [DOI]
Wissing, S.A., Muller, RH. (2003). Cosmetic applications for solid lipid nanoparticles (SLN) Int J Pharm 254(1): 65-68. [DOI]

Wissing, S.A., Kayser, O., Muller, R.H. (2004). Solid lipid nanoparticles for parenteral drug delivery. Adv Drug Deliv Rev 56(9): 1257-1272. [DOI]

Wong, H.L., Rauth, A.M., Bendayan, R., Manias, J.L., Ramaswamy, M., Liu, Z., Erhan, S.Z., Wu, X.Y. (2006) A new polymer-lipid hybrid nanoparticle system increases cytotoxicity of doxorubicin against multidrug-resistant human breast cancer cells. Pharm Res. 23(7): 1574-1585 [DOI]

Yang, S., Zhu, J., Lu, Y., Liang, B., Yang, C., (1999). Body distribution of camptothecin solid lipid nanoparticles after oral administration. Pharm Res 16(5): 751-757. [DOI]

Yassin, A.E.B., Anwer, M.K., Mowafy, H.A., El-Bagory, I.M., Bayomi, M.A., Alsarra, I.A. (2010). Optimization of 5fluorouracil solid-lipid nanoparticles: a preliminary study to treat colon cancer. Int J Med Sci 7(6): 398-408 [DOI]

Zhang, X., Zhang, H., Wu, Z., Wang, Z., Niu, H., Li, C. (2008). Nasal absorption enhancement of insulin using PEGgrafted chitosan nanoparticles. Eur J Pharm Biopharm 68(3): 526-534. [DOI]

Zur Muhlen, A., Mehnert, W. (1998). Drug release and release mechanisms of prednisolone loaded solid lipid nanoparticles. Pharmazie 53: 552-555. 